\title{
Analysis of the use of thermoelectric generator and heat pipe for waste heat utilization
}

\author{
Imansyah Ibnu Hakim ${ }^{1, *}$, Nandy Putra ${ }^{1}$, and Mohammad Usman ${ }^{1}$ \\ ${ }^{1}$ Heat Transfer Laboratory, Department of Mechanical Engineering, University of Indonesia, Kampus UI, Depok, 16424, Indonesia
}

\begin{abstract}
Waste heat recovery is one way to reduce the use of fossil fuels, one of them is by using thermoelectric generator to convert waste heat into Thermoelectric Generator (TEGs) is a module that can convert heat into electrical power directly, using Seebeck effect and Peltier effect as its working principle, so it can increase efficiency of energy consumption by utilizing waste heat from an instrument that generate waste heat. The focus of this research is to find the output voltage of TEG by utilizing the temperature difference on the cold side and the heat side of the TEGs. The heat side of the module will be given heat from the heater as a simulation of the heat from hot water, and on the cold side heat pipes will be used to remove the heat on the cold side of TEGs. The result, output voltage that generated by using 4 module TEGs that arranged to Thermal Series - Series Circuit and using 2 heat pipes is 2.1-volt, and then it is possible to use for phone charger.
\end{abstract}

\section{Introduction}

Currently, the world's energy needs are increasing as the population increases and is due to developments in various industries. Most of the energy that comes from fossil fuels causes higher amounts of carbon dioxide in the environment, causing problems such as global warming, climate change, acid rain, and ozone depletion. [1]. And since the Industrial Revolution in the 19th century, the concentration of carbon dioxide in the atmosphere has increased significantly, from 280 parts per million (ppm) to $401 \mathrm{ppm}$ [2]. Another issue to note is the depletion of fossil fuel reserves that are constantly being used. From this effort to meet current energy needs, many alternative energy development programs are being undertaken, such as the utilization of wind energy, solar cell, OTEC (Ocean Thermal Energy Conversion), etc. Besides efforts on energy conservation and savings are also widely done, one of which is an effort made to improve the efficiency of energy use. Because by saving energy or increasing the efficiency of energy use, it will be able to extend the depletion of fossil-derived materials and can reduce the impact of environmental destruction [3].

Improving thermal efficiency are very important, as currently thermal efficiency of gas and steam power plants or other thermal systems is only about $30-40 \%$, although there are already some technologies used to utilize such waste heat, for example combine cycle system, but still the heat discharged into the environment is still considerable [3].

With the amount of energy wasted in the form of heat wasted into the environment, increasing thermal efficiency needs to be done, one of them by using a thermoelectric module generator that can directly convert heat into electric power by utilizing the temperature difference.

The thermoelectric effect has been discovered more than 100 years ago and became applicable around 1950 which led to the discovery of thermoelectric generators (TEGs) based on the Seebeck effect as a new technique of energy conversion. TEGs are solid state devices with the advantages of no-moving parts, low noise, long service life, small size, light weight, and high stability. The main deficiencies in TEGs are low efficiency (about $5 \%$ ) and high cost [4].

In recent years, thermoelectric technology has received much attention to be used for waste heat recovery [5]. The exhaust heat recovery system is useful for exploiting the wasted heat to be converted into electrical power. This electric power can be used to charge the car battery in order to reduce the load of the car alternator thereby potentially reducing fuel consumption, so $\mathrm{CO}_{2}$ emissions also have the potential to decrease [6].

In general, the energy used in fossil fuel combustion engines, used $25 \%$ for car propulsion, $30 \%$ for cooling, $5 \%$ for parasitic losses, and $40 \%$ for exhaust gases. In diesel trucks that use $100 \mathrm{~kW}$ of energy from fuel, it shows that $30 \mathrm{~kW}$ is wasted into heat in vehicle exhaust. If the lost energy is converted into electrical energy, even with $3 \%$ efficiency, $900 \mathrm{~W}$ can generate electricity. Based on the Fiat Research Center, 800-1000 Wel means $12-14 \mathrm{~g} / \mathrm{km} \mathrm{CO} 2$ reduction [7].

Multi-national car companies like BMW [8], Ford [9], Honda [10], and Renault [11] have demonstrated their interest in exhaust heat recovery, by developing such systems using TEGs. Generally, the tested system utilizes heat from the exhaust and uses engine coolant to lower the temperature on the cold side of the TEGs module [6].

\footnotetext{
* Corresponding author: imansyah@eng.ui.ac.id
} 
For the use of thermoelectric modules as electrical generators, some components may be helpful to the performance of the thermoelectric module (e.g. heat exchangers) to strengthen the heat transfer process between modules and heat sources in order to achieve greater temperature difference. An electric converter is used to convert the resulting electric voltage to match the desired voltage [7].

In this research, the heat exchanger used to cool the cold side of the thermoelectric module is Heat pipe, which is a passive heat exchanger with very high conductivity [6]. With the use of heat pipes on the cold side of the thermoelectric module, the heat transfer process on the thermoelectric module will be greater, potentially increasing the temperature difference on the hot and cold side of the thermoelectric module.

The purposes of this research are to determine the amount of electrical energy that can be produced, the efficiency of thermoelectric module used, and the best configuration of thermoelectric.

\subsection{Experiment with Heater as Heat Source}

In this first experiment the objective is to know the output voltage that generated from thermoelectric module and best arrangement of thermoelectric that will be tested. The first experimental setup is shown in Fig 1. The heat source is from heater with temperature varies from $80,75,70,65$, and $60{ }^{\circ} \mathrm{C}$ will be given on the hot side of the module. The temperature of heater will be set by adjusting the voltage that given to heater with voltage regulator. On the cold side of the thermoelectric module heat will be removed with heat pipe by free convection. The thermoelectric arrangement that will used in this experiment is shown in Fig 2.

Generated voltage from thermoelectric module will be collected by data acquisition (DAQ) module. The DAQ module will send signal to computer through USB cable. The signal will be processed by programming language in LabView software, which will display and record the voltage data in real time. At the same time, temperature on the hot side and cold side of thermoelectric module will be collected by temperature sensor, $\mathrm{K}$ type thermocouple that is connected to DAQ module, in order to record the temperature data into LabView software.

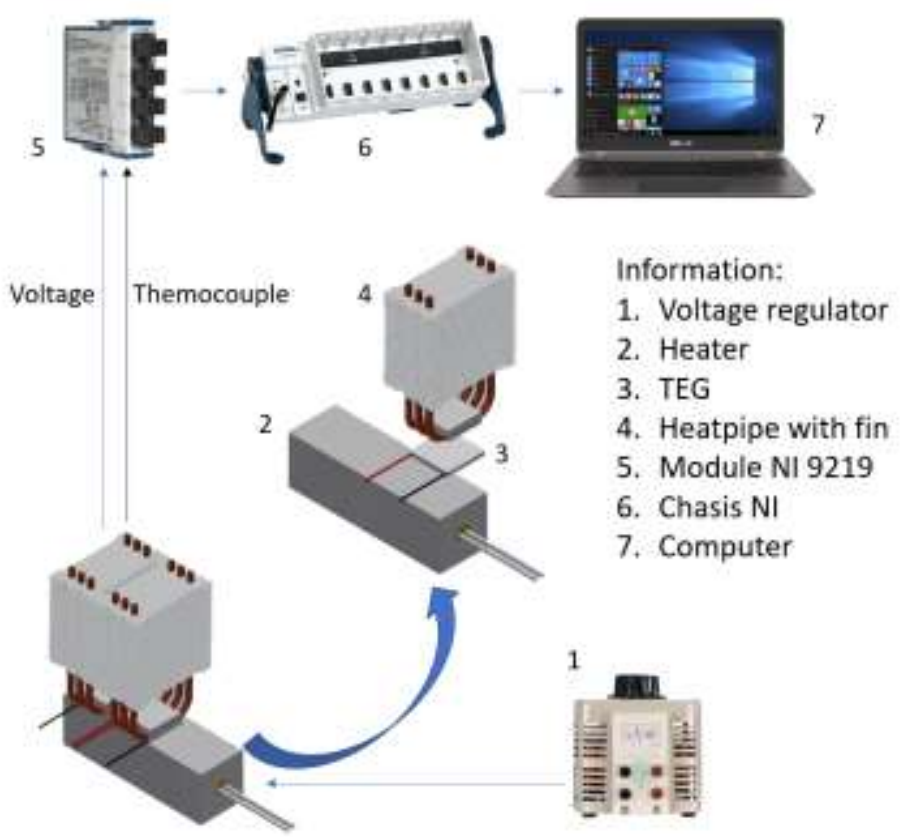

Fig. 1 The first schematic arrangement of thermoelectric and heat pipe test device 

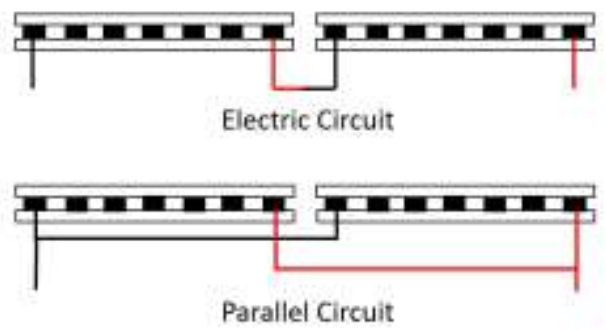

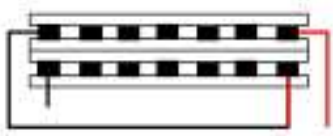

Thermal Series

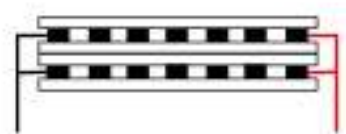

Thermal Parallel
Fig. 2. The thermoelectric arrangement

\subsection{Experiment with Hot Water as Heat Source}

In this experiment, thermoelectric will be tested with hot water as a heat source, and heat pipe as a heat exchanger for the cold side of thermoelectric module. The schematic arrangement of this experiment is shown in Fig 3. The hot water will be placed in a cup made of stainless steel. Heat from the cup_will be used as a heat source for the hot side of thermoelectric module supported by heat collector as shown in Fig. 4 to provide a flat surface for thermoelectric module.

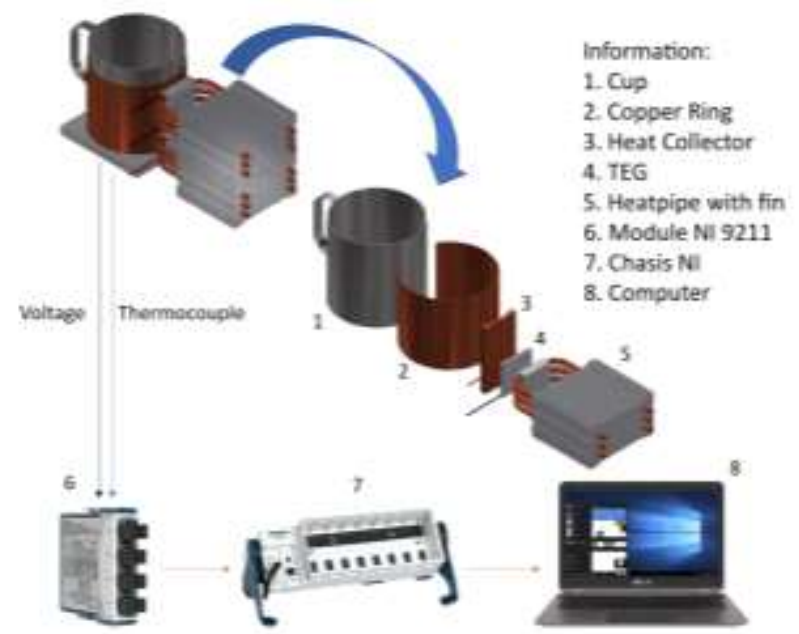

Fig. 3. The second schematic arrangement of thermoelectric and heat pipe test

Thermoelectric arrangement of this experiment is based on the result on the first experiment, which arrangement shows the highest output voltage. The goal of this experiment is to get sufficient output voltage for charging a mobile phone, where the required voltage is about 5 volts.

Unlike in the first experiment where the temperature of heat source is set to be stable or constant, in this experiment the heat source from hot water is gradually decreased from high to low temperature. The purpose is to find out how much voltage is generated and how long it can produce enough power for charging the mobile phone.

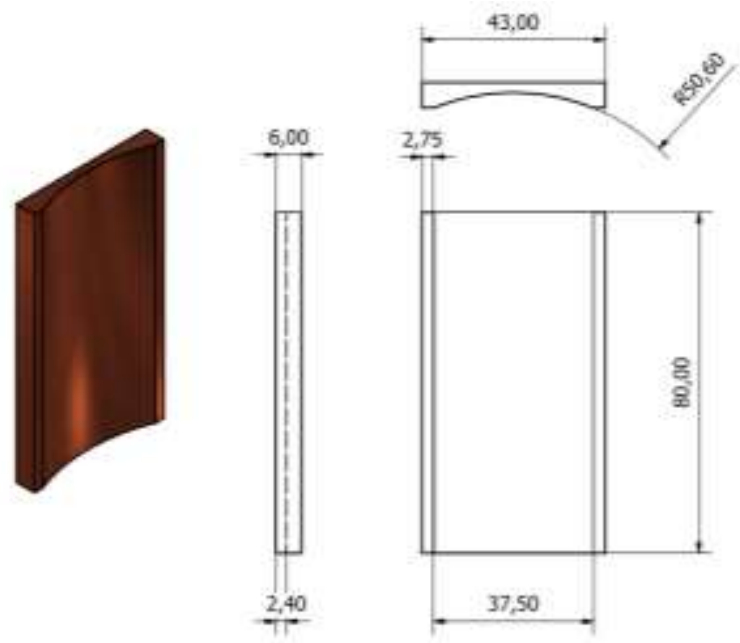

Fig. 4. Heat Collector Made of Copper

To analyse the performance of the thermoelectric module, a thorough understanding of Seebeck coefficient $(\alpha)$ is needed. The Seebeck coefficient describes the raising voltage (electromotive force) due to the temperature difference which becomes very important. Seebeck coefficient can be expressed by the following equation [12].

$$
\alpha=\frac{\Delta V}{(T h-T c)}
$$

Where $\Delta \mathrm{V}$ is the generated voltage or voltage difference, Th is temperature on the hot side of module and $\mathrm{Tc}$ is temperature on the cold side of module.

And for the generated electric current (I) is given by the following equation.

$$
I=\frac{\alpha \times \Delta T}{(R i+R L)}
$$

Where $R_{i}$ is the internal resistance of the thermoelectric module and $\mathrm{R}_{\mathrm{L}}$ is the external load.

The rate of heat transfer of input $\left(\mathrm{Q}_{\mathrm{h}}\right)$ from heat source $T_{h}$ (hot junction) at temperature $T_{c}$ (cold junction) is as the following equation.

$$
\mathrm{Q}_{\mathrm{h}}=\left(\alpha I T_{h}\right)+K\left(T_{h}-T_{c}\right)
$$

Where $K$ is the sum of thermal conductivity of the module elements $\left[\mathrm{W} /{ }^{\circ} \mathrm{C}\right]$.

The thermoelectric performance can be evaluated from the total output power $(\mathrm{P})$ and the thermoelectric efficiency $(\eta)$ which can be defined as the following equation [5].

$$
P=I^{2} R_{L}
$$

Where $\mathrm{I}$ is electric current and $\mathrm{R}_{\mathrm{L}}$ is the external resistance of the thermoelectric module 


$$
\eta=\frac{P}{Q h}
$$

\section{Analysis and discussion}

\subsection{The Graph Result and Thermoelectric Generator Test Using Heater}

In this experiment, thermoelectric was tested using a heater and adjusted to temperatures of $60,65,70,75$, and $80{ }^{\circ} \mathrm{C}$ using voltage regulator. Heat from the heater will be used as a heat source on the hot side of the TEG module, and the cold side the TEG module will be cooled using heat pipe by free convection. In this test, TEG module will also be tested by varying the arrangement as shown in Figure 2 using 1, 2, and 4 TEG modules, so there will be nine arrangements to be tested.

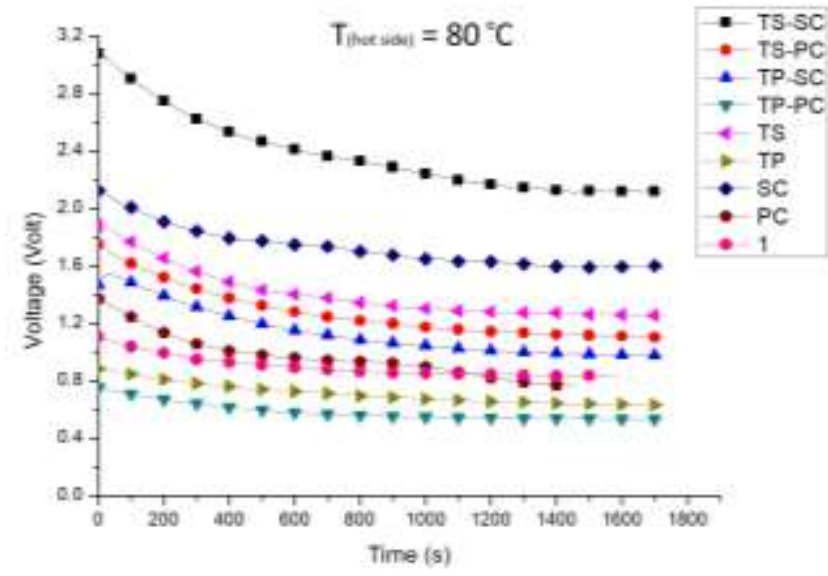

Fig. 5. The Result of Thermoelctric Generator Test Using Heater $\left(\mathrm{T}_{\text {hot side }}=80^{\circ} \mathrm{C}\right)$

The result showed the comparison of the output voltage of the nine arrangements that have been tested is shown in Fig 5. In that graph, it is clear that the Thermal Series - Series Circuit (TS-SC) which consists of 4 TEG modules and 2 heat pipes, shows the best results by generating the largest output voltage with 2.1 Volt.
Followed by Series Circuit (SC) with 1.6 Volt consisting of 2 TEG modules and 1 heat pipe, Thermal Series (TS) which uses 1 heat pipe with 1.2 Volt, Thermal Series Parallel Circuit (TS-PC) with 1.1 Volt, Thermal Parallel - Series Circuit (TP-SC) with 0.98 Volt, 1 TEG module with 0.8 Volt, Parallel Circuit (PC) with 0.77 Volt, Thermal Parallel (TP) with 0.63 Volt, and Thermal Parallel - Parallel Circuit (TP-PC) with 0.53 Volt.

From that graph, it can be seen that the arrangements which generated the greatest voltage are the thermoelectric that arrayed with series circuit, the TS-SC which is essentially an arrangement of four thermoelectric coupled with series circuits but arranged in two stacks, as well as the arrangement of SC and TS. This can happen because the series circuit arrangement will indeed magnify the voltage by summing the voltage generated from each module. Whereas for the arrangement of parallel circuits will produce a larger electric current by summing the electric current generated from each module. These two arrangements can also be combined as in the arrangement of TS-PC and TP-SC to generate voltage and electric current as needed.

Table 1 shows the results obtained on each test, and it can be seen that the largest output voltage is generated by TS-SC arrangement, while the smallest voltage is generated by TP-PC arrangement, even though both arrangements used the same components.

From the Table 1, it can also be seen that the arrangement of the use of the thermoelectric module has a considerable influence to achieve the desired voltage. and in this research, it can be seen that the composition of TS-SC can produce the greatest voltage and can reduce the use of heat exchangers. so that in subsequent studies of thermoelectric, the use of thermoelectric arrangements needs to be considered.

The comparison of TEG module performance is also determined by using external load of $10 \mathrm{ohm}$ and various temperature difference, as shown in Table 2 .

The data in Table 2 is the average value when the stable condition has been reached. The performance of

Table 1. Voltage Results

\begin{tabular}{|c|c|c|c|c|c|c|}
\hline \multirow{2}{*}{ Arrangement } & \multirow{2}{*}{ Component } & \multicolumn{5}{|c|}{ Voltage (volt) } \\
\hline & & $60^{\circ} \mathrm{C}$ & $65^{\circ} \mathrm{C}$ & $70^{\circ} \mathrm{C}$ & $75^{\circ} \mathrm{C}$ & $80^{\circ} \mathrm{C}$ \\
\hline $1 \mathrm{TEG}$ & 1 TEG, 1 heatpipe & 0,52 & 0,59 & 0,67 & 0,77 & 0,84 \\
\hline Thermal Series (TS) & 2 TEG, 1 heatpipe & 0,76 & 0,8 & 0,9 & 1.05 & 1,2 \\
\hline Thermal Parallel (TP & 2 TEG, 1 heatpipe & 0,37 & 0,37 & 0,47 & 0,5 & 0,62 \\
\hline Series Circuit (SC) & 2 TEG, 2 heatpipe & 0,9 & 1,12 & 1,23 & 1,35 & 1,6 \\
\hline Parallel Circuit (PC) & 2 TEG, 2 heatpipe & 0,46 & 0,54 & 0,62 & 0,68 & 0,77 \\
\hline TP-SC & 4 TEG, 2 heatpipe & 0,64 & 0,71 & 0,87 & 0,95 & 0,97 \\
\hline TP-PC & 4 TEG, 2 heatpipe & 0,34 & 0,37 & 0,43 & 0,48 & 0,53 \\
\hline TS-SC & 4 TEG, 2 heatpipe & 1,3 & 1,4 & 1,8 & 1,94 & 2,1 \\
\hline TS-SPC & 4 TEG, 2 heatpipe & 0,7 & 0,78 & 0,9 & 1.05 & 1,1 \\
\hline
\end{tabular}


TEG module tends to increase as the temperature on the hot side of the module increase.

Table 2. Comparison Performance of TEG module with Temperature Variations

\begin{tabular}{|l|l|l|l|l|l|}
\hline $\begin{array}{l}\text { Hot Side } \\
\text { Temperature } \\
\left({ }^{\circ} \mathrm{C}\right)\end{array}$ & $\begin{array}{l}\text { Temperature } \\
\text { Difference }\left({ }^{\circ} \mathrm{C}\right)\end{array}$ & $\begin{array}{l}\text { Electric } \\
\text { Current } \\
(\mathrm{A})\end{array}$ & $\begin{array}{l}\text { Power } \\
\text { Generated } \\
(\mathrm{W})\end{array}$ & $\begin{array}{l}\text { Rate of } \\
\text { Heat } \\
\text { Transfer }\end{array}$ & $\begin{array}{l}\text { TEG } \\
\text { Efficiency }\end{array}$ \\
\hline 60 & 17.59 & 0.080 & 0.064 & 14.51 & $0.44 \%$ \\
\hline 65 & 20.15 & 0.093 & 0.086 & 16.68 & $0.52 \%$ \\
\hline 70 & 23.12 & 0.108 & 0.116 & 19.19 & $0.60 \%$ \\
\hline 75 & 25.75 & 0.120 & 0.144 & 21.44 & $0.67 \%$ \\
\hline 80 & 27.85 & 0.139 & 0.194 & 23.39 & $0.83 \%$ \\
\hline
\end{tabular}

\subsection{The Graph Result and Thermoelectric Generator Test Using Hot Water}

4 TEG modules are arranged to TS-SC and utilizing heat from hot water in a stainless-steel cup. From the graph above, it can be seen that temperature is measured at several points, including water temperature ( $\mathrm{T}$ water), surface temperatures pod for glass made of copper ( $T$ ring), hot side temperature of TEG module ( $\mathrm{T}$ hot side), cold side temperature of TEG module ( $\mathrm{T}$ cold side), and room temperature ( $\mathrm{T}$ ambient).

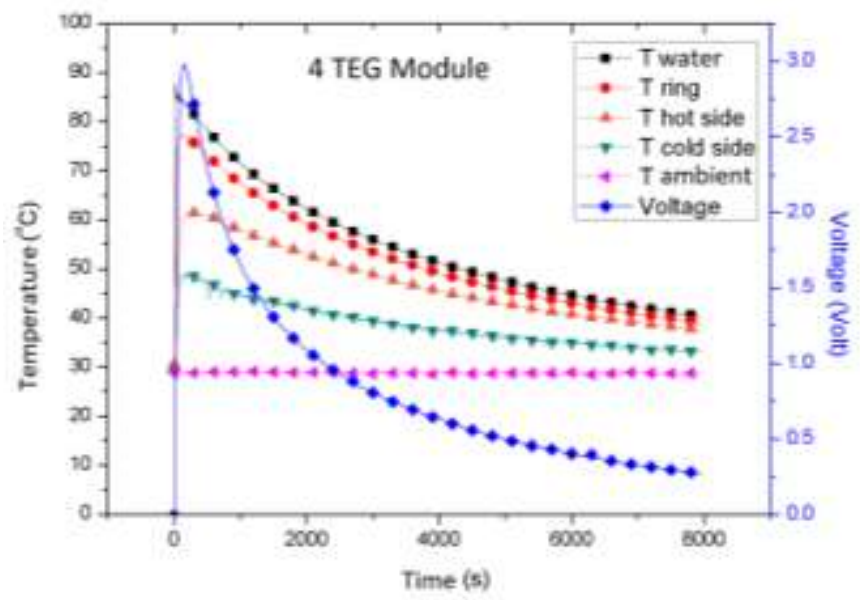

Fig. 6. Test Result 4 TEG Module with Hot Water in a Cup

In the process of heat transfer from hot water to the hot side of the module ( $\mathrm{T}$ water $-\mathrm{T}$ ring $-\mathrm{T}$ hot side) there is a decrease in temperature, which results in smaller value of heat that can be utilized. This is caused by heat loss due to the thermal resistance of the material used (stainless steel glass, copper plate rings as pods, and copper pieces to connect the TEG module).

This test brings in the result of maximum voltage of 3 volts. This amount of voltage is generated at some time after the glass is filled with hot water, heat pipe is initially in ambient temperature and the hot side is instantaneously releasing heat from the water. As the time goes on temperature difference become quite large, and eventually the generated voltage will decrease along with the decrease in water temperature and temperature difference on the hot side and cold side of module.

The generated power of TEG Module is to be applied to charge mobile phones where the required voltage is 5 volts. Since the voltage generated in this test does not meet the needs that has to be achieved, a 2-5volt DC-DC step-up USB module is used which can raise and stabilize the voltage with 2 to 5 volts input into stable output at 5 volts. Using this module, the output voltage of the 3-volt TEG module can be used as an input for the USB charging module. This result in continuous phone charging as long as the voltage generated by the TEG module is more than 2 volts.

From the graph in Fig. 6, it can be seen that voltage generated from 4 TEG modules is above 2 volts for 10 minutes, indicated by using this equipment that can charge mobile phone for 10 minutes. This charging process is still not effective, due to the current flowing only around $100 \mathrm{~mA}$, while the wall charger in general drains $1000 \mathrm{~mA}$. Therefore, in order to achieve the same result of capacity as the common mobile phone charger, this testing tools will take ten times longer.

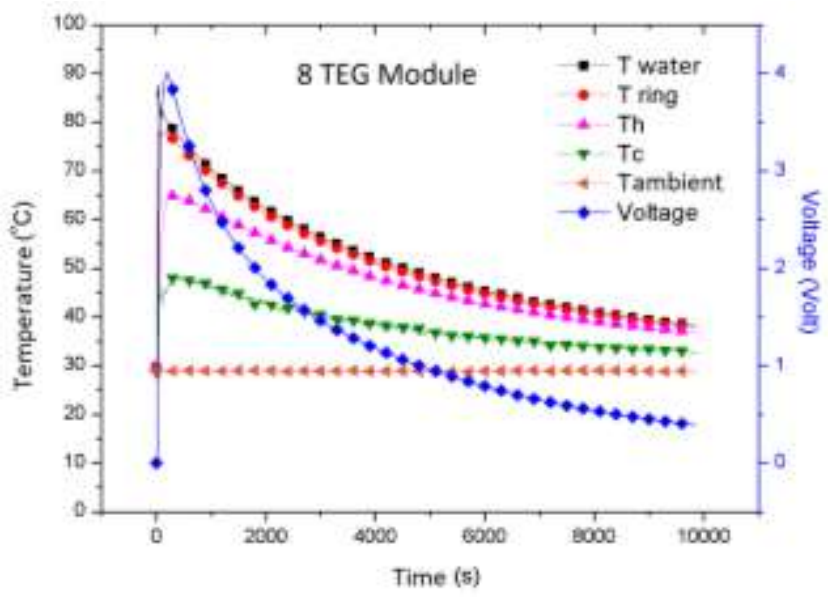

Fig. 7. Test Result 8 TEG Module with Hot Water in a Cup

From Fig. 7, it can be seen that data of temperature and voltage generated changing over time. Using 8 TEG modules and 4 heat pipes, this device produces a maximum of 4 volts. The change of temperature in the graph above (Fig. 7) shows the same result, i.e. a considerable drop in temperature from the water temperature to the hot side of the thermoelectric module.

From the results obtained the voltage generated from the eight thermoelectric modules still has not reached 5 volts, which is the voltage required to charge the mobile phone. With the maximum voltage obtained at 4 volts (does not produce double the voltage from the use of 4 TEG modules), while the resistance in the circuit is doubled compared with the use of 4 TEG modules, the electric current generated in this series becomes smaller compared to the use of 4 TEG modules. This is also indicated by the inability to use step-up module DC-DC 2-5 volts. Due to that, 8 TEG module series cannot be done charging the phone.

Based on the basic principle, arranging 2 electrical sources in series will double the output voltage, but in this experiment, the output voltage generated is only 4 volts, whereas in the experiment using 4 TEG modules generated 3 volts. This can happen because of the losses that occur along the path of the TEG module circuit, so 
that with the length of the path that is strung, the losses that occur will be greater.

The same thing is also seen in previous experiments using heater as a heat source. The TP-PC arrangement produces the smallest output voltage even though it uses 4 TEG modules which is a doubling of the Thermal Parallel (TP) arrangement, where it should be the same in accordance with the principle of the electric parallel connection.

\section{Conclusion}

In the first experiment where the heater was used as a heat source, the results shows TS-SC arrangement generated the greatest votage with 2.1 Volt.

In this experiment it can also be seen that the arrangement of the use of thermoelectric modules has a considerable influence. The TS-SC arrangement can produce the greatest voltage and can save the use of heat exchangers. So that in subsequent studies of thermoelectric, the use of thermoelectric arrangements needs to be considered.

TEGs module performance is also determined by using 10-ohm load, the greatest efficiency occurred in the test of TS-SC arrangement with temperature $80{ }^{\circ} \mathrm{C}$ with $0.83 \%$.

A second test using hot water as a heat source, obtained a maximum voltage of 3 volts on the use of 4 TEG and 4 Volt modules on the use of 8 TEG modules, these results indicate incompatibility with the basic principle which states that arranging 2 electrical sources in series will double the output voltage. This can happen because of the losses that occur along the path of the TEG module circuit.

Charging the phone with a series of hot water test devices in a glass using 4 TEG can be done with the help of step-up module DC-DC $2-5 \mathrm{~V}$, but not effective because the current is only $100 \mathrm{~mA}$, while the charger current is generally $1000 \mathrm{~mA}$.

The authors thank the Directorate of Research and Community Service, Universitas Indonesia, for funding this research through the PITTA Scheme No. 2452/UN2.R3.1/HKP.05.00/2018.

\section{References}

1. P. Aranguren, M. Araiz, D. Astrain, and A. Martínez, "Thermoelectric generators for waste heat harvesting: a computational and experimental approach," Energy Conversion and Management, vol. 148, pp. 680-691, (2017)

2. E. A. Setiawan and M. Asvial, Renewable Energy's Role in a Changing World (no. 8). (2016)

3. N. Putra, R. A. Koestoer, M. Adhitya, A. Roekettino, and B. Trianto, "Potensi
Pembangkit Daya Termoelektrik untuk Kendaraan Hibrid," Makara Teknologi, vol. 13, no. 2, pp. 53-58, (2009)

4. Q. Ma, H. Fang, and M. Zhang, "Theoretical analysis and design optimization of thermoelectric generator," Applied Thermal Engineering, vol. 127, pp. 758-764, 2017.

5. D. M. Rowe, CRC handbook of thermoelectrics. CRC press, (1995)

6. B. Orr, A. Akbarzadeh, and P. Lappas, "An exhaust heat recovery system utilising thermoelectric generators and heat pipes," Applied Thermal Engineering, (2016)

7. D. Champier, "Thermoelectric generators: A review of applications," Energy Conversion and Management, vol. 140, pp. 167-181, (2017)

8. J. LaGrandeur, D. Crane, S. Hung, B. Mazar, and A. Eder, "Automotive waste heat conversion to electric power using skutterudite, TAGS, PbTe and BiTe," in Thermoelectrics, 2006. ICT'06. 25th International Conference on, (2006), pp. 343-348: IEEE.

9. Q. E. Hussain, D. R. Brigham, and C. W. Maranville, "Thermoelectric exhaust heat recovery for hybrid vehicles," $S A E$ International Journal of Engines, vol. 2, no. 2009-01-1327, pp. 1132-1142, (2009)

10. M. Mori, T. Yamagami, M. Sorazawa, T. Miyabe, S. Takahashi, and T. Haraguchi, "Simulation of fuel economy effectiveness of exhaust heat recovery system using thermoelectric generator in a series hybrid," SAE International Journal of Materials and Manufacturing, vol. 4, no. 2011-01-1335, pp. 1268-1276, (2011)

11. N. Espinosa, M. Lazard, L. Aixala, and H. Scherrer, "Modeling a thermoelectric generator applied to diesel automotive heat recovery," Journal of Electronic materials, vol. 39, no. 9, pp. 1446-1455, (2010)

12. A. N. Eddine, D. Chalet, X. Faure, L. Aixala, and P. Chessé, "Optimization and characterization of a thermoelectric generator prototype for marine engine application," Energy, vol. 143, pp. 682-695, (2018) 